\section{DEVELOPMENT OF BERAPAK COMPOSITE AS A CORE MATERIAL FOR HIGH RESILIENT SPORTS EQUIPMENT}

\author{
Soovirehn A/L Epeng \\ University Malaysia Sarawak \\ Mastika Lamat \\ University Malaysia Sarawak \\ Muhammad Firdaus Abong Abdullah \\ University Malaysia Sarawak
}

Corresponding Author

soovirehnepeng@yahoo.com
The berapak (bamboo internal skin) is a material produced from bamboo that has the potential to be made as the alternative materials to replace timber and polymers. Studies by researchers have shown that berapak material is suitable for manufactured products with high endurance like bicycle frameworks and automotive components. Research identifying the potential of this material is still at its early stages. Experiments with different types of adhesives have shown variations in terms of strengths and compression levels. There are three samples produced to test the berapak material resistance level. The first sample consists of $100 \%$ berapak material, the second sample is of a carbon fibre composite and the third sample is of a glass fibre composite. Results from the tests carried out indicate there are differences in the resistance level, sample weight and test graphs.

Keywords: berapak, composite, potential, resilience 


\section{INTRODUCTION}

'Berapak' is a term in the Bidayuh which refers to the internal layers of the skin of bamboo or bamboo inner skin, (Figure 1). Berapak is usually obtained from a young bamboo and from zollingeri Schizostachyum (buluh lemang) genus variety, or also known as pansuh bamboo among the people in Sarawak. It consists of various sizes depending on the size of the bamboo, and the common size that is used to produce the berapak by entrepreneurs is $40 \mathrm{~cm}$ to $60 \mathrm{~cm}$ long, while the width is within $15 \mathrm{~cm}$ to $20 \mathrm{~cm}$. The berapak size depends on how big and how long the bamboo segment is. Usually, the berapak's thickness is around $2 \mathrm{~mm}$. However, it is not consistent because process of peeling the bamboo skin is done manually. This research discusses the results of berapak strength using different composites, adhesives, arrangements.
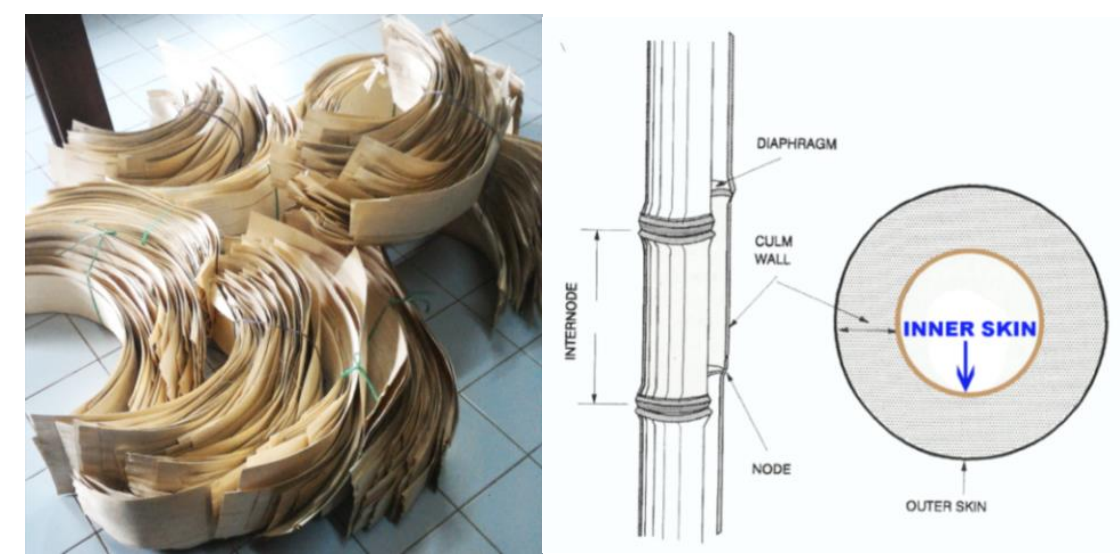

Figure 1: Berapak

\subsection{The use of composite materials}

Currently composite materials are used in many field, generally composite materials are used to make various items and tools (Idowu et al., 2015). In the automotive field, especially composite materials are widely used in the auto parts division due to its lightweight and durable properties (Ragahavendra, Varada, Ramachandra \& Hemachandra, 2010). The properties of this composite material can meet vehicle manufacturing criteria which require minimum weight for oil savings and other factors (Seki et al., 2014). In addition, this material is also used to make vehicle brakes due to its heat-resistant properties and also good grip strength (Ma et al., 2012). 


\subsection{Potential and advantages of bamboo composite materials}

The factors that enable bamboo to be developed as a composite material are low cost and its properties can be harder than glass when made into composite material (Saravana \& Mohan, 2010). The advantages of this bamboo composite material have been used as a substitute for wood (Huang, Hse, \& Shupe, 2015). This action can help reduce the volume of timber raw material production decreasing today (Saxena et al., 2008). The success in producing this composite causes bamboo fiber to be known as natural glass fiber (Osorio, Trujillo, Van Vuure \& Verpoest, 2011). In addition, bamboo also has high mechanical strength, cheap and has a lot of raw material. Many raw material factors enable this material to be developed, (Boukehili \& Nguyen-Tri, 2012).

\section{EXPERIMENT ON ADHESIVE, COMPOSITE AND ARRANGEMENT}

\subsection{Processing material with composite element addition}

The berapak that has gone through the basic processes of straightening, compressing and cutting the berapak according to the sample size, will be processed with different composite elements (Figure 2). The researcher provided eighteen samples which used different composite materials, adhesives and arrangements of the berapak. The composite materials used are carbon fibre and glass fibre. In addition, the adhesive materials used are Kangaroo 508 QD hight solid PVA, bond Duro adhesive 820 and adhesive Contact adhesive 505.

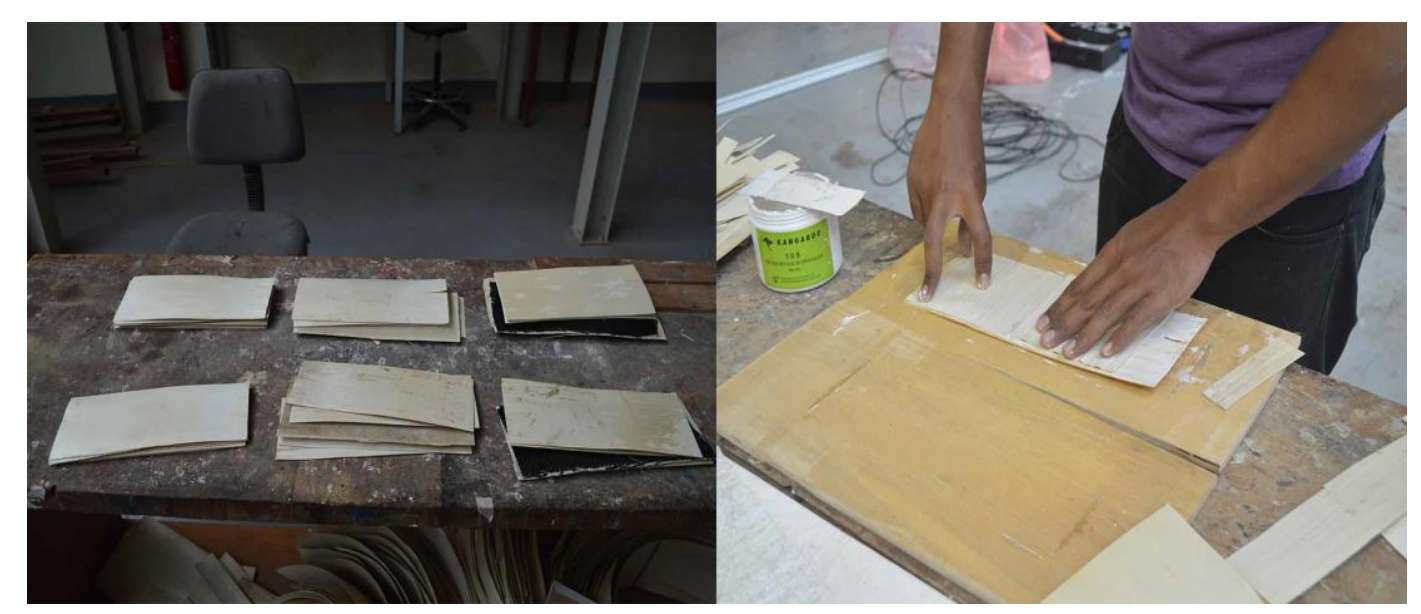

Figure 2: Processing material with composite element addition

The adhesive materials suitable for wood and plywood are using. Codings were used in every sample to avoid confusion in data gathering (Figure 3). The first sample group 
namely A1, A2, A3, B1, B2, and B3, used Kangaroo 508 QD high solid PVA glue. Samples A1, A2 and A3 were arranged in parallel, while samples B1, B2 and B3 were arranged by cross. Samples $A 1$ and $B 1$ were $100 \%$ berapak, while samples $A 2$ and B2 had composite carbon fibre. Samples A3 and B3, on the other hand, used composite fibre Glass. Sample 2 used Duro bond 820 glue and the third sample used Contact adhesive 505. However, the composite material used and the way they were arranged were similar to sample 1.

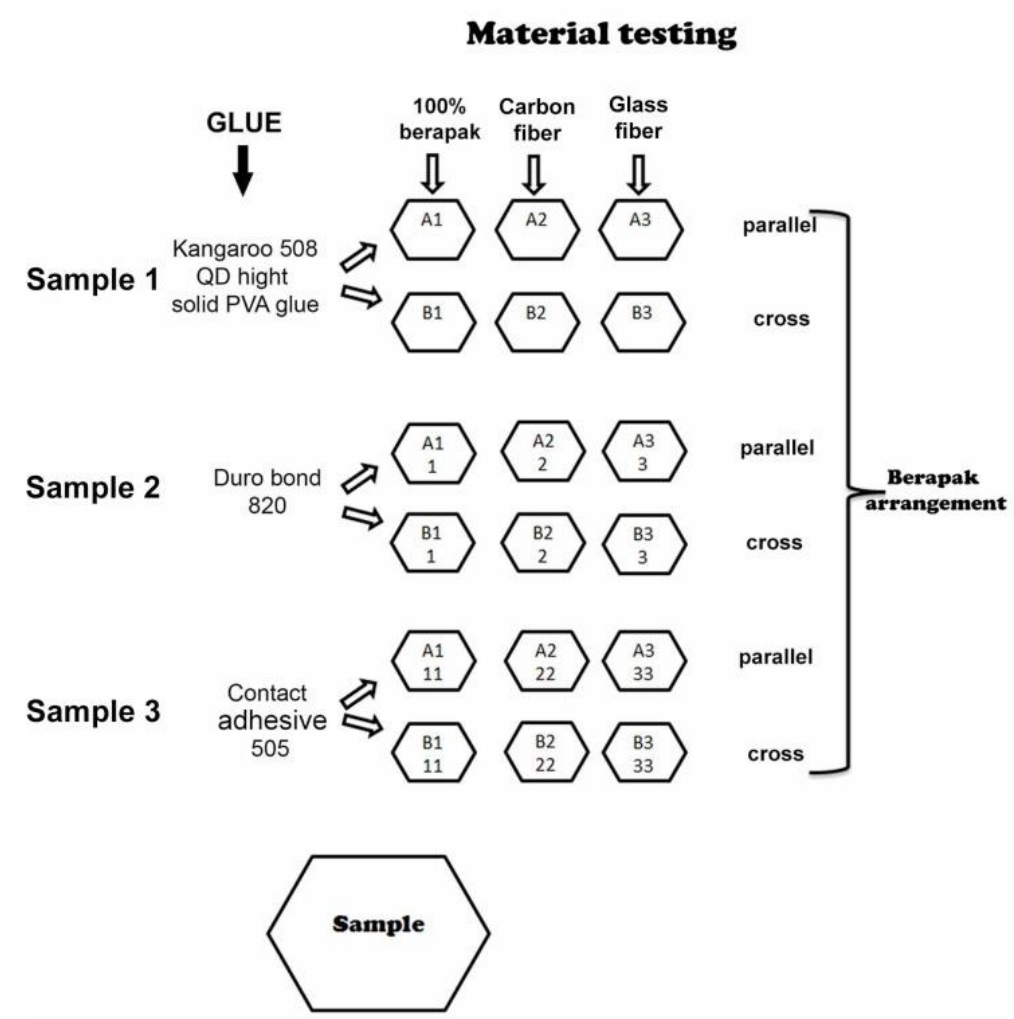

Figure 3: Material testing

\subsection{Sample size}

Every sample had the same measurement which was $30 \mathrm{~cm}$ long, $10 \mathrm{~cm}$ wide and 1 $\mathrm{cm}$ thick (Figure 4). The Samples were tested to identify the strength of the composite material used. 

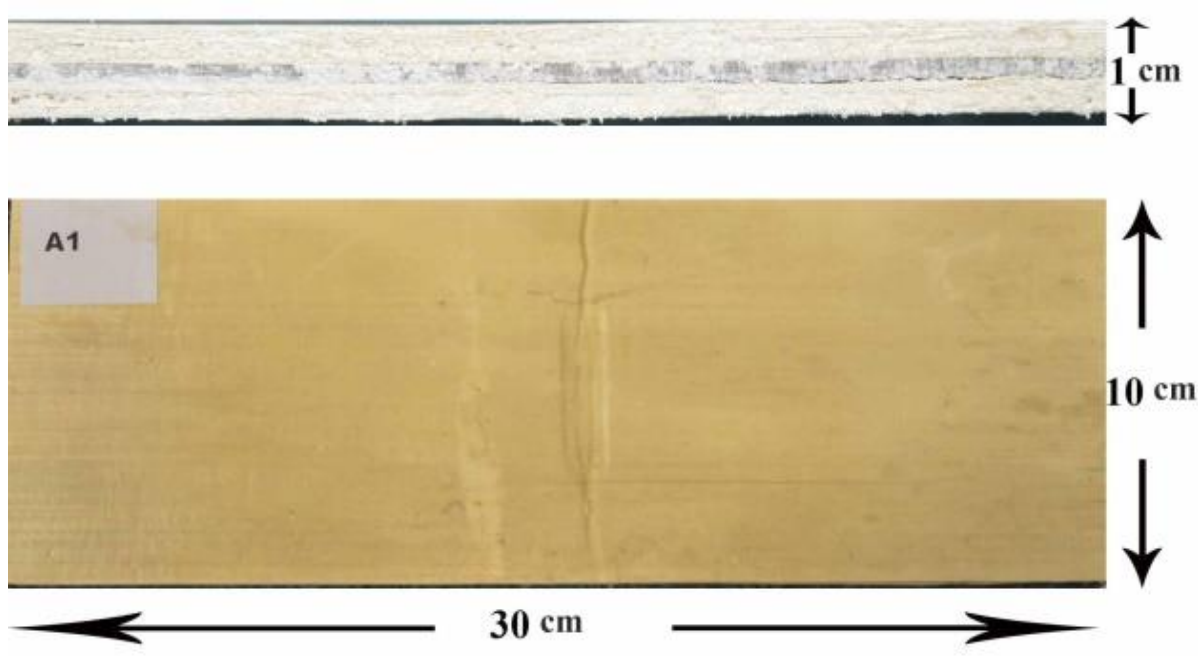

Figure 4: Sample size

\subsection{Adhesive test result}

Table 1 shows test results carried out on adhesive usage. The test was done to identify an adhesive suitable for Berapak. Varied results were obtained in the test.

Table 1: Adhesive test result

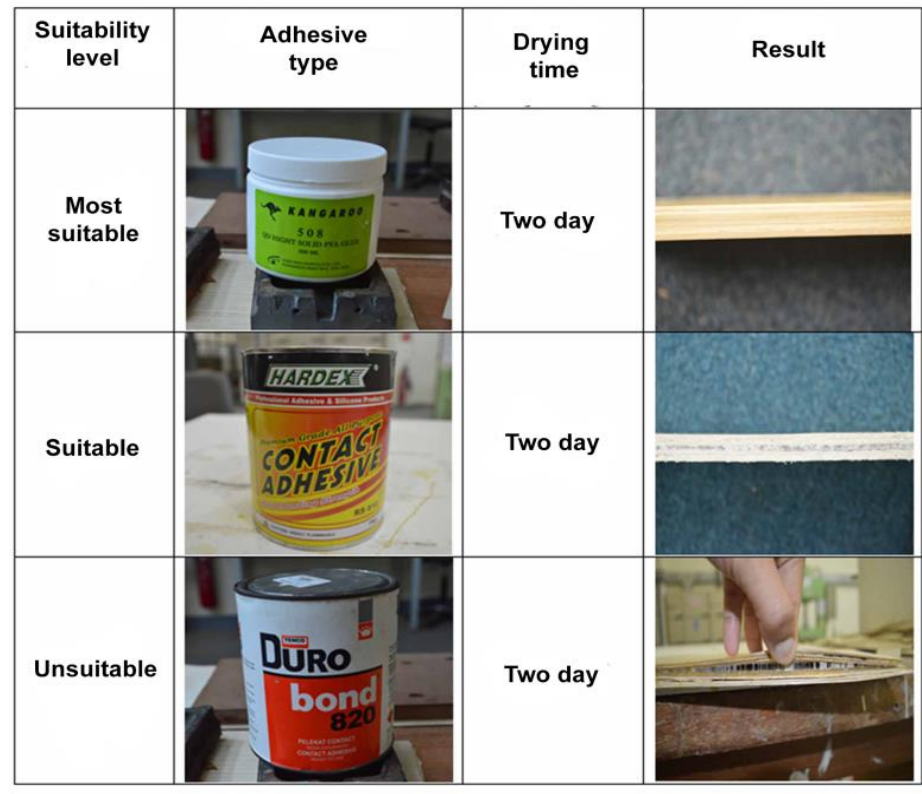

\subsection{Discussion of finding}

The results showed that the kangaroo adhesive 508 QD high solid PVA is the most suitable as the berapak material can stick well. On the other hand, though the Contact adhesive RS810 adhesive for material 3 was also found to be suitable, the drying time is longer. The hand Duro bond adhesive 820 for material 2 however, is unsuitable for gluing berapak as it takes a much longer time to dry and does not stick well on berapak. 


\section{STRENGTH TESTING}

\subsection{Mechanical strength test material}

The aim of the test was to determine the strength levels of the berapak using different composites and arrangements. After that, three samples were chosen according to the categories to produce products. The testing processes used the Mechanical testing machine with a 3-point bending format (Figure 5).

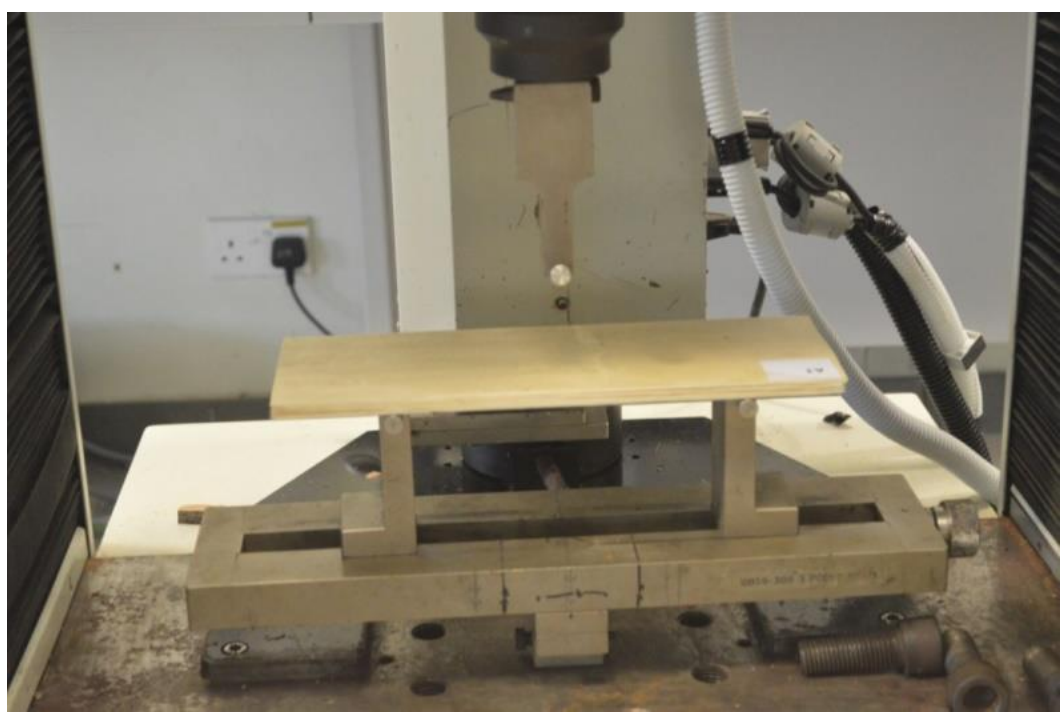

Figure 5. Mechanical strength test material

\subsection{Testing result}

Table 2 shows test results from all the samples that were tested. Sample for material 2 was not tested because the adhesive used failed at the first level. In conclusion, based on the test results achieved the researcher found material 1 had a higher resistance level compared to material 3. Overall, the lowest resistance level for material 1 is $0.41438 \mathrm{kN}$ which is the B1 sample, where the berapak was arranged using the cross method, while the highest resistance level, is $0.78281 \mathrm{kN}$, which is sample A3, where the berapak arranged in parallel.

This resistance level difference proved that the samples arranged in parallel were stronger compared to the samples which were arranged by cross pattern. However, the data achieved depended on the sample size produced namely, $30 \mathrm{~cm} \times$ length 10 $\mathrm{cm}$ broad $\times 1 \mathrm{~cm}$ thick. While material 3 is also lower in its resistance level, between $0.20625 \mathrm{kN}$, which is B111 sample, the berapak arrangement method is cross and the highest resistance level is $0.3375 \mathrm{kN}$ which is the $\mathrm{B} 333$ sample. 
Table 2: Berapak resistance level

\begin{tabular}{|c|c|c|c|c|c|}
\hline \multicolumn{2}{|c|}{$100 \%$ berapak } & \multicolumn{2}{c|}{ Carbon fibre } & \multicolumn{2}{c|}{ Glass fibre } \\
\hline A1 & 0.51375 & A2 & 0.77438 & A3 & 0.78281 \\
\hline B1 & 0.41438 & B2 & 0.50063 & B3 & 0.6675 \\
\hline A111 & 0.24844 & A222 & 0.30187 & A333 & 0.3075 \\
\hline B111 & 0.20625 & B222 & 0.21375 & B333 & 0.3375 \\
\hline
\end{tabular}

Results from the test on $\mathrm{A} 1$ sample indicated that its maximum strength level was $0.51375 \mathrm{kN}$. However, this value decreased drastically to lower than $0.3 \mathrm{kN}$. The maximum disposal level was $17.019 \mathrm{~mm}$; the maximum stress level was $13.8713 \mathrm{~mm} 2$ / N; and the maximum level of tension was $3.15167 \%$ (Figure 6).

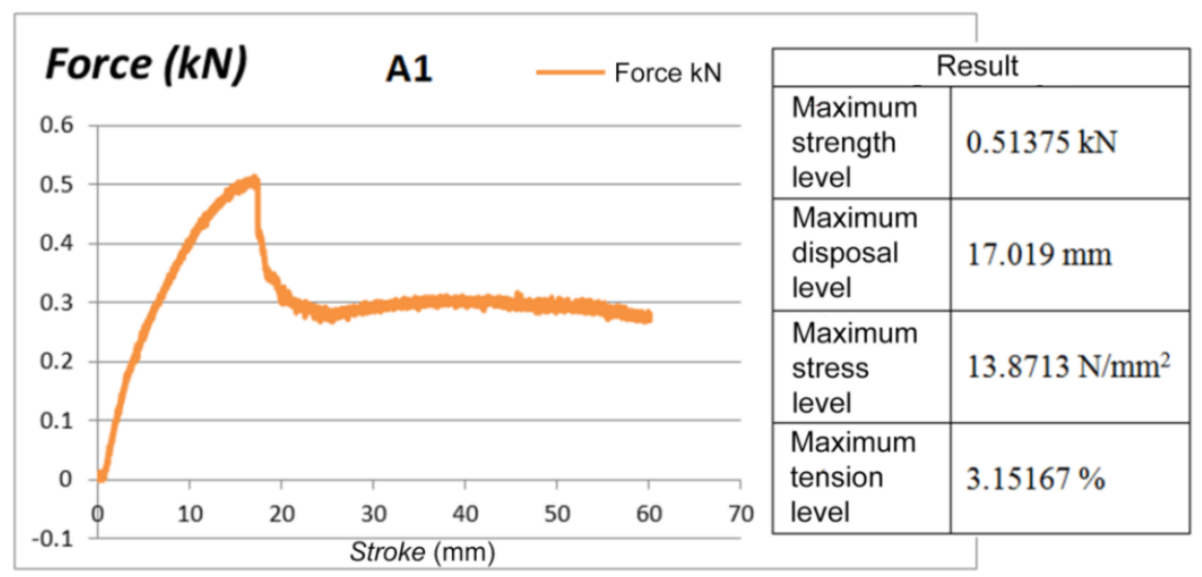

Figure 6: Testing result $\mathrm{A} 1$

Test towards A2 sample found that the maximum strength level was $0.77438 \mathrm{kN}$. Nevertheless, it decreased drastically to below $0.2 \mathrm{kN}$ at 22 stroke per $\mathrm{mm}$. The maximum disposal level was $19.393 \mathrm{~mm}$; the maximum stress level was $20.9081 \mathrm{~mm} 2$ / $\mathrm{N}$; and the maximum level of tension was $3.5913 \%$ (Figure 7).

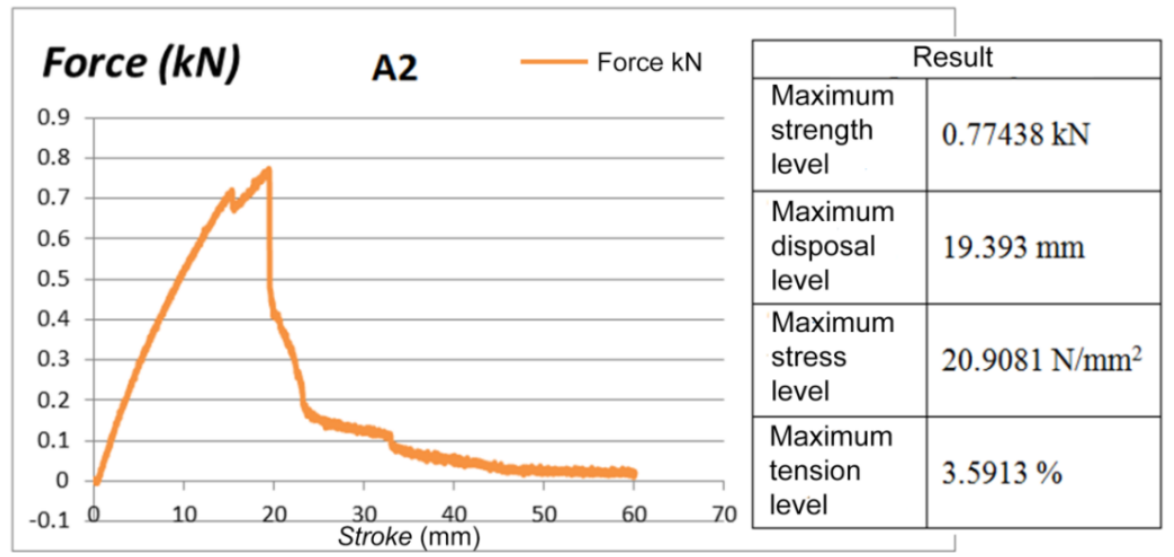

Figure 7: Testing result $\mathrm{A} 2$ 
Test on sample A3 indicated that the maximum strength level was $0.78281 \mathrm{kN}$, and decreased slightly to below $0.7 \mathrm{kN}$. The maximum disposal level was $14.808 \mathrm{~mm}$, while the maximum stress level was $17.6133 \mathrm{~mm} 2 / \mathrm{N}$, and the maximum level of tension is at $2.74222 \%$ (Figure 8 ).

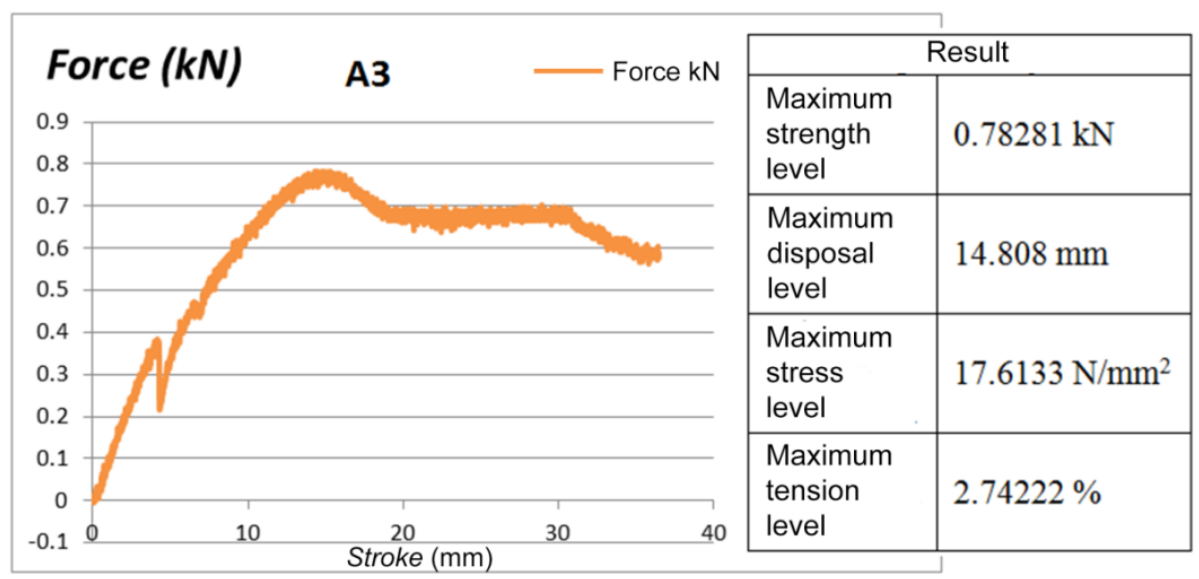

Figure 8: Testing result $\mathrm{A} 3$

\subsection{Composite material resistance level difference}

After the 3-point bending test conducted against the samples, the results of sample A1 which used $100 \%$ berapak was still stuck perfectly and did not break. On the other hand, A2 sample which used composite carbon fibre, while was still stuck, broke at the bottom layer. The results of sample A3 which used glass fibre was broken between the composite material and the berapak. This proved that the adhesive used for material 1 did not stick firmly to the glass fibre (Figure 9).

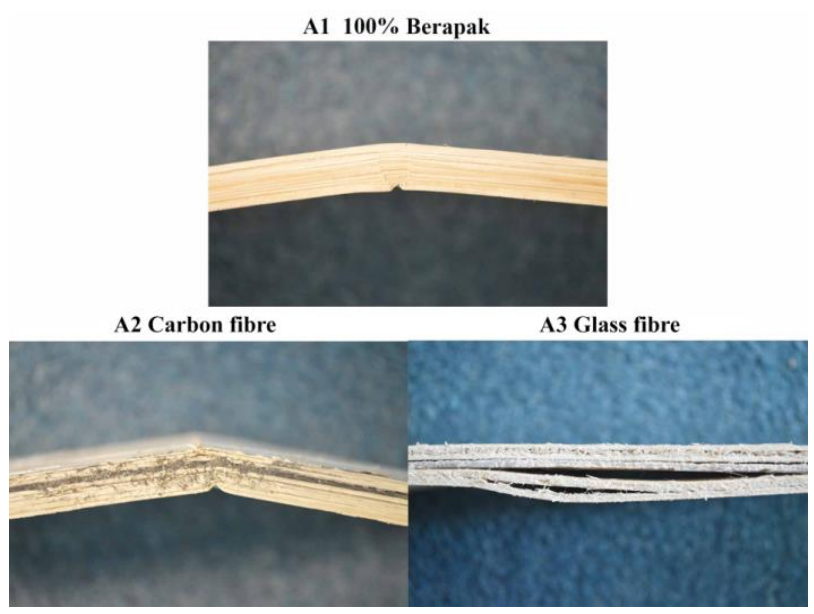

Figure 9: Composite material resistance level difference

Table 3 shows the sample with the highest resistance level. All samples with highest resistance level used the Kangaroo adhesive 508 QD high solid PVA and were arranged in parallel. 
Table 3: Sample with highest resistance level

\begin{tabular}{|c|c|c|c|}
\hline Sample & A1 & A2 & A3 \\
\hline Glue & $\begin{array}{c}\text { Kangaroo 508 QD } \\
\text { hight solid PVA }\end{array}$ & $\begin{array}{c}\text { Kangaroo 508 QD } \\
\text { hight solid PVA }\end{array}$ & $\begin{array}{c}\text { Kangaroo 508 QD } \\
\text { hight solid PVA }\end{array}$ \\
\hline Berapak arrangement & Parallel & Parallel & Parallel \\
\hline Resistance level & 0.51375 & 0.77438 & 0.78281 \\
\hline Composite metarial & $100 \%$ berapak & Carbon fibre & Glass fibre \\
\hline
\end{tabular}

\section{CONCLUSION}

The differences in every sample tested in terms of arrangements, composites materials and adhesive materials used. In terms of adhesive used, Kangaroo adhesive 508 QD hight solid PVA is most suitable to be used for the berapak material based on the resistance level produced. The Duro bond adhesive 820 for sample group 2 is not suitable because it did not stick firmly and takes longer time to dry. The Contact adhesive RS810 adhesive, though suitable lower resistance level compared to adhesive 1. Different arrangement patterns also influenced the sample resistance level. The berapak arranged in parallel is stronger compared to the cross pattern. Sample A1 arranged in parallel had a resistance level of $0.51375 \mathrm{kN}$ compared to sample B1 arranged in cross pattern, which had a resistance level of only $0.41438 \mathrm{kN}$. In addition, the composite materials used also influenced the samples' strength level. All three A1, A2 and A3 samples produced different resistance.

The strength level for sample A1 which used $100 \%$ berapak was $0.51375 \mathrm{kN}$, while sample A2 which used carbon fibre composite material was $0.77438 \mathrm{kN}$, and sample A3 which used glass fibre composite material was $0.78281 \mathrm{kN}$. The results of this test proved that sample $A 3$ is stronger compared to the samples that used other composite materials. Sample A2 was stronger compared to sample A1. While in terms of weight, the sample that used $100 \%$ berapak was the lightest, followed by the sample which used carbon fibre. The heaviest sample was the glass fibre. Adhesive materials used also had different weights. The sample using the Kangaroo adhesive 508 QD high solid PVA was much lighter compared to the sample using the Contact adhesive RS810 adhesive.

\section{REFERENCES}

1. Boukehili, H. \& Nguyen-Tri, P. (2012). Helium gas barrier and water obsorption behavior of bamboo fibre reinforcd recycled polypropylene. Journal of Reinforced Platics and Composites, 31(23), 1638-1651. 
2. Huang, X. D., Hse, C. Y. \& Shupe, T. F. (2015). Evaluation of the Performance of the Composite Bamboo/Epoxy Laminated Material for Wind Turbine Blades Technology. Bioresources, 10(1), 660-671.

3. Idowu, D. I., Tamba, J., Rotimi, E. S., Williams, K. K., Stephen, C. A. \& Gbenga, E. (2015). The use of polypropylene in bamboo fibre composites and their mechanical properties - A review. Journal of Reinforced Plastics and Composites, 34(16), 13471356.

4. Ma, Y., Shen, S., Tong, J., Ye, W., Yang, Y. \& Zhou, J. (2012). Effects of bamboo fibre on friction performance of friction materials. Journal of Thermoplastic Composite Material, 26(6), 845-859.

5. Osorio, L., Trujillo, E., Van Vuure, A. W. \& Verpoest, I. (2011). Morpological aspects and machanical properties of single bamboo fibres and flexural characterization of bamboo/epoxy composites. Journal of Reinforced Plastics and Composites, 30(5), 396-408.

6. Ragahavendra, R. H., Varada, R. A., Ramachandra, R. G. \& Hemachandra, R. K. (2010). Flexural and Compressive Properties of Bamboo and Glass Fibrereinforced Epoxy Hybrid Composites. Journal of Reinforced Plastic and Composites, 29(10), 1446-1449.

7. Saravana, B. D. \& Mohan, K. (2010). Potential use of nature fiber composite material in India. Journal of Reinforced Plastics and Composites, 29(24), 36003613.

8. Saxena, M., Morchhale, R. K., Asokan, P. \& Prasad, B. K. (2008). Plant FibreIndustrial Waste Reinforced Polymer Composites as a Potential Wood Substitute Material. Journal of Composite Materials, 42(4), 367-382.

9. Seki, Y., Seki, Y., Sarikanat, M., Sever, K., Durmuskahya, C. \& Bozaci, B. (2014). Evaluation of linden fibre as a potential reinforcement material for polymer composites. Journal of Industrial Textiles, 29(1), 1-14. 